\title{
Understanding Current Challenges in Evaluating Environmental Impacts for Aggregate Producers through a Case Study in Western Sweden
}

\author{
Christina Lee *(D), Panagiota Papadopoulou $\mathbb{D}$, Gauti Asbjörnsson, Erik Hulthén (D) and Magnus Evertsson
}

check for

updates

Citation: Lee, C.; Papadopoulou, P.; Asbjörnsson, G.; Hulthén, E.; Evertsson, M. Understanding Current Challenges in Evaluating Environmental Impacts for Aggregate Producers through a Case Study in Western Sweden. Sustainability 2022, 14, 1200. https://doi.org/10.3390/su14031200 Academic Editor: Jacek Michalak Received: 10 December 2021 Accepted: 7 January 2022 Published: 21 January 2022 Publisher's Note: MDPI stays neutral with regard to jurisdictional claims in published maps and institutional affiliations.

Copyright: (c) 2022 by the authors. Licensee MDPI, Basel, Switzerland. This article is an open access article distributed under the terms and conditions of the Creative Commons Attribution (CC BY) license (https:// creativecommons.org/licenses/by/ $4.0 /)$.

\author{
Department of Industrial and Materials Science, Chalmers University of Technology, 41296 Gothenburg, Sweden; \\ ppapa@kth.se (P.P.); gauti@chalmers.se (G.A.); erik.hulthen@chalmers.se (E.H.); \\ magnus.evertsson@chalmers.se (M.E.) \\ * Correspondence: leec@chalmers.se
}

\begin{abstract}
To improve environmental performance of a product or activity, an understanding of the environmental impacts associated with it is needed. Quantification of environmental impacts can be achieved through the standardized measurement-based tool of Life Cycle Assessment (LCA). However, challenges occur when trying to apply a standardized tool to a nonstandardized industry such as the aggregate industry. This study aims to provide greater understanding of the challenges facing the aggregate industry, particularly producers, in applying LCA. This was conducted through a literature review, to establish the current understanding of challenges, accompanied by a case study where a site-specific LCA was conducted with a large enterprise at a crushed-rock-production facility in western Sweden, to gain new industry-specific insight. A total of 13 challenges were identified: seven methodological and six systemic. Out of these 13 challenges, 3 were deemed a high risk to the implementation of LCA by aggregate producers, and 3 to the integrity of results. A best-practice framework is suggested to incorporate LCA into current environmental management techniques utilized at quarry sites in Sweden to overcome some challenges. However, LCA used for environmental management should not lead to double work if LCA is being utilized for Environmental Product Declarations, and further research is encouraged to find appropriate solutions with the most efficient allocation of the resources needed in conducting LCA studies.
\end{abstract}

Keywords: aggregates; life cycle assessment; LCA; environmental management; Sweden; quarry; mining; environmental performance

\section{Introduction}

Quarrying and mining can lead to a variety of local and global environmental impacts, including, but not limited to, groundwater contamination, biodiversity loss, resource depletion, noise pollution, land degradation, and emissions of greenhouse gasses (GHGs) and particulate matter (PM10) [1-3]. However, due to the major differences between operations, these impacts vary significantly from site to site. Although actions are being taken to reduce some impacts, engagement varies highly between countries; and a lack of transparency, a lack of data leading to omissions, and a slow uptake of ambitious environmental goals are a few of the issues putting the mining and quarrying industries off track for achieving global environmental targets and the Sustainable Development Goals (SDGs) [4-6]. This study will focus on the extraction of aggregates, and for clarification, the term quarrying will be used to relate to any mining activity that has the main purpose of producing aggregate products.

Aggregates account for the largest nonenergy mining sector in Europe, and produced over 3 billion tons of aggregate in 2018 across 39 different countries [7]. Aggregates can be sourced from sand and gravel deposits, marine deposits, crushed rock, artificial sources (made from byproducts, e.g., fly ash or blast furnace slag), and recycled/reused 
material where crushed rock accounts for approximately half of all aggregate production in Europe [7]. The application of aggregates is wide and varied, from sewage treatment to railway ballast, as well as being a key element in some solutions for environmental concerns, for instance flood defenses. However, most aggregates in Europe are used in construction and infrastructure projects as it constitutes the main component in concrete and asphalt. With the extensive and wide use of aggregates, it is essential that the environmental performance of their production is in line with new proposals from the EU Commission to achieve a $55 \%$ net reduction in greenhouse gasses by 2030 as part of the European Green Deal [8].

Understanding the environmental impacts associated with a service or product can lead to improvements in environmental performance. In theory, this can be achieved through environmental management techniques, for example: environmental impact assessment (EIA), environmental management systems (EMS), standards and monitoring, and risk assessment; the choice of technique depends on the situation and desired outcomes [9-11]. However, to gain a quantitative evaluation of impacts, measurement or value-based tools are needed [12]. Life Cycle Assessment (LCA) is a popular measurementbased tool utilized in environmental management $[9,12]$ and will be the methodology in focus for this study, to evaluate environmental impacts.

LCA is a continuously developing, standardized methodology for applying life cycle thinking to model environmental impacts from a particular product or service [11,13]. Life cycle thinking is founded in considering the entire life span of an activity or object, and therefore, considers a product from 'cradle to grave', i.e., from mineral extraction, through manufacturing, production, and use to disposal $[9,10]$. The key phases of an LCA study are outlined in the ISO standard 14001:2015 [10] and should be considered for a deeper understanding of the LCA methodology.

The standardized nature of LCA can cause issues when being applied in a nonstandardized industry, such as quarrying, where large variations in production systems are commonplace. Many LCA studies rely on databases for key input and output data for the system, which generally rely on industry or country averages, and can poorly represent the system in question. As a consequence, misleading or inaccurate conclusions can be drawn, impacting the integrity of the results [14]. Quarrying systems are also of a dynamic nature, producing multiple products, with production activities and inputs heavily reliant on customer demands. This means production inputs and outputs often vary significantly from year to year and even month to month, which is difficult to capture using current established LCA practices $[15,16]$. However, improvements are continuously being evaluated and implemented to address the concerns with LCA, especially within the construction sector, making LCA a relevant and important methodology to the aggregate industry $[17,18]$. Nevertheless, as more producers seek to gain Environmental Product Declarations (verified certificates based on an LCA study for business-to-business communication for products, commonly known as EPDs), an increase in producers undertaking LCA studies has been witnessed [19], expanding the demand for LCA beyond experts. Having a clear understanding of the challenges for implementing reliable LCA studies in the aggregate industry is needed by producers to address potential pitfalls in conducting LCA studies, and can help identify solutions that encourage the uptake of LCA among producers. No such comprehensive resource specific to challenges for aggregate producers in Sweden could be found by the authors at the time of publishing.

Considering the unique circumstances surrounding aggregate producers in conducting LCA studies discussed above, the aim of this study is to provide a summary of current challenges facing the industry related to applying LCA for evaluating environmental impacts, and the risk these challenges pose to broad implementation and reliability of LCA studies. Initial challenges to LCA practitioners in the aggregate industry are identified in the current literature, with further challenges specific to producers identified in an inductive approach through a revelatory case study as defined by Yin [20] in western Sweden. From the challenges identified, a framework for environmental management for aggregate producers 
is suggested to contribute to more robust and transparent environmental practices in the industry. This study will focus on aggregate production from crushed rock to identify sector-specific needs, and can help further research be tailored to the needs of producers.

Section 2 describes the methodologies used to identify the challenges. The results from the literature review and the case study are presented in Sections 3.1 and 3.2, respectively. The overall impact of these challenges are brought together and discussed in Section 4 , with a brief conclusion presented in Section 5 .

\section{Materials and Methods}

The study was conducted in two phases: the first consisted of a literature review of peer-reviewed papers published in English since 2010, to establish the current state of knowledge on challenges in conducting LCA studies for aggregate products noted by researchers. During the second phase of the study, an LCA study was conducted with a large enterprise in western Sweden on a crushed rock operation to establish specific challenges for producers conducting LCA studies in an inductive approach. A simple risk assessment has been made for each identified challenge to assess the likelihood of the challenge hindering the implementation of LCA by producers and the possibility of the challenge impacting the integrity of the results of the LCA study in terms of accuracy. The risk assessment was conducted qualitatively through discussions among the authors of this paper to assign a low, medium, or high risk depending on the perceived likelihood of impact, i.e., a high risk has a high likelihood of impact.

For the literature review in phase one, a Scopus search within the article title, abstract, and keywords with the terms 'Life Cycle', 'quarry', and 'aggregate' was conducted. This yielded 30 results, which dropped to 13 results when 'concrete' and 'asphalt' were excluded from the search. The number increased to 35 results when 'quarry' is exchanged with 'mining'. Out of the returned results, seven were related to crushed rock aggregates, and therefore deemed relevant to the current study [1,2,14,21-24]. Further sources were identified through citations in the above papers and through recommendations from researchers at the Chalmers Rock Processing Systems (CRPS) research group [3,25-32], resulting in 16 in total.

In the case study, qualitative methods were utilized to gain an ethnographic understanding of the challenges for producers by conducting an LCA study in conjunction with a large enterprise. The mini-ethnographic case study, as defined by Fusch et al. [33], was conducted over 6 months at a single quarry site and included conducting informal interviews with key personnel, actively participating in and observing the process, and examining internal documents. The LCA conducted on the study site followed the methodology framework outlined in the ISO 14040:2006 and 14044:2006 standards [10,34]. Modelling tools identified in the literature review and those used within the company itself were utilized for the Life Cycle Impact Assessment (LCIA) phase and as a source for secondary data (The Aggregates Industry Life Cycle Assessment Model: an open-source tool developed in Excel by Imperial College London in collaboration with the Waste \& Resource Action Programme for the aggregate industry in the UK, accessed upon request; and commercial LCA software with connected databases for secondary data where GaBi was the specific software utilized). LCA guidelines developed by the Sustainable Aggregate Resource Management project (SARMa) were used to aid in the goal and scope definition, particularly when considering system boundaries [26].

\section{Results}

The results highlighted two different areas of challenges for producers in evaluating environmental impacts: those associated with conducting the LCA itself, referred to as methodological challenges, and those associated with the implementation of LCA by producers for environmental management, referred to as systemic challenges. The challenges impacted the LCA in various stages of the study, which have been described based on 
the stages outlined in ISO 14040:2006. The results from the two phases of the study are presented below.

\subsection{Phase One: Literature Review}

From the literature review, seven challenges were identified: four methodological, and three systemic, none of which were deemed high risk to the implementation of LCA by producers. A summary of the challenges is given in Table 1.

Table 1. Summary of identified challenges for evaluating environmental impacts using LCA in the aggregate industry from a review of current published literature.

\begin{tabular}{|c|c|c|c|c|c|}
\hline $\begin{array}{l}\text { Challenge } \\
\text { Classification }\end{array}$ & & Identified Challenge & Impact Stage & $\begin{array}{l}\text { Risk to Imple- } \\
\text { mentation of LCA }\end{array}$ & $\begin{array}{l}\text { Risk to Integrity of } \\
\text { Results from LCA }\end{array}$ \\
\hline \multirow{4}{*}{ Methodological } & 1. & $\begin{array}{l}\text { Challenges in accurately allocating } \\
\text { environmental burdens per product }[24,26] \text {. }\end{array}$ & $\begin{array}{l}\text { Inventory Analysis } \\
\text { (Allocation) }\end{array}$ & Low & Medium \\
\hline & 2. & $\begin{array}{l}\text { Lack of impact categories that accurately } \\
\text { reflect key environmental impacts for the } \\
\text { industry }[28,30] .\end{array}$ & LCIA & Low & Low \\
\hline & 3. & $\begin{array}{l}\text { Significant life-cycle variations over a } \\
\text { temporal scale are difficult to incorporate } \\
{[24,26,35]}\end{array}$ & $\begin{array}{c}\text { Goal and Scope } \\
\text { (system boundaries) }\end{array}$ & Low & Medium \\
\hline & 4 . & Limited secondary data sources [32] & $\begin{array}{l}\text { Inventory Analysis } \\
\text { (Data quality) }\end{array}$ & Low & Medium \\
\hline \multirow{3}{*}{ Systemic } & 5. & Unstandardized production process $[2,14,21]$. & $\begin{array}{l}\text { Goal and Scope (system } \\
\text { boundaries), Inventory } \\
\text { Analysis (Data collection) }\end{array}$ & Medium & Low \\
\hline & 6. & Limited goals for the LCA study $[1,21,23]$. & Goal and Scope & Low & Low \\
\hline & 7. & Lack of appropriate tools $[23-25,29,31]$. & $\begin{array}{l}\text { Inventory Analysis } \\
\text { (Data collection), LCIA }\end{array}$ & Medium & Medium \\
\hline
\end{tabular}

The methodological challenges were linked to allocation, impact categories, inventory analysis and setting system boundaries. Difficulties with allocation are discussed by Blengini and Garbarino [26], where it is highlighted how issues with using allocation per product can occur due to the interconnectivity of the production process linked to, for example, internal reprocessing loops and the lack of process-separated data. This makes it difficult to determine exactly which burdens should be associated with which product, and would make allocation based solely on mass, often suggested by LCA standards, an inaccurate solution. This challenge has led some practitioners to avoid product-specific allocation, opting for allocating an overall burden from production to aggregates, removing the ability to compare products [24]. Although the allocation procedure can impact the results per product [36], resulting in a medium risk assignment, it is not deemed a significant risk to implementation by producers, as decisions regarding the allocation process, particularly for economic allocation methods, can be easily justified based on current reporting standards $[10,34,37]$.

Some key environmental impacts that are not quantified effectively in current LCIA impact categories are resource use and land-use change, as well as local impacts such as on biodiversity $[28,30]$. Although a resource-depletion category does exist for minerals and metals in the standard EN 15804:2012 + A2:2019 [37], it does not effectively reflect other issues surrounding the depletion of gravel or sand resources, and caution should be used if applying it to aggregate product LCA studies [28,30,37]. Biodiversity and landuse change are not just challenges for the aggregate industry but pose issues for LCA practitioners universally [38]. It can be particularly challenging to quantify biodiversity impacts for quarries, as certain sites have provided unique ecosystems for rare species to flourish after mine closure [39,40]. However, despite these impacts being critical to a holistic view of environmental impacts, the lack of their inclusion at this stage is not seen as a risk to implementation of LCA by producers. If no impact is calculated, the risk to the results is also low, however, if these categories are attempted to be calculated using poorly 
representative methods, the risk could be much higher. Variations between characterization models for impact categories were also noted by Segura-Salazar and Tavares [24] as an issue impacting results, consistent with general LCA challenges for practitioners [41].

The third challenge identified in the methodological classification was linked to the setting of system boundaries in a temporal frame. Unlike some manufacturing processes, quarrying can cover several life-cycle phases within a relatively short time, which cover the mine, asset and product life cycles, as described in the guidelines given by Blengini and Garbarino [26]. These could have an influence on the environmental impacts of aggregate products produced at a quarry site with a short lifespan, yet are difficult to incorporate into a standardized LCA methodology in an effective and feasible way [37]. Again, this challenge is seen to have higher risk on the quality and representativeness of an LCA study rather than implementation itself and is, therefore, deemed a medium risk to the results and a low risk to implementation.

The last challenge was associated with a lack of secondary data sources, specifically for mine assets, which led to their exclusion by Rosado, Vitale, Penteado and Arena [32]. Further challenges with secondary data sources were also noted in the case study and are discussed in more detail in Section 4.

Turning to the systemic challenges identified, the first challenge was associated with the high variability between sites, which makes it almost impossible to gain worthwhile results for environmental management from secondary data alone [2,14,21]. As it is unlikely that production will become more standardized in the future due to the geological and logistical variations of operations, specific guidelines and tools for the industry were developed to aid the uptake of LCA within the industry at the end of the 2000's [3,26]. The development of both aids has, however, dropped off, with no updates to the projects in the last 10 years, likely due to the industry's turn towards standardized tools during this period. The industry now often utilizes standards for LCA, particularly for producing Environmental Product Declarations (EPDs), which are declarations mainly used for business-to-business communication, rather than improving environmental performance. Without guidance tools for conducting an LCA, results can vary significantly between studies, leading to a medium risk to the accuracy of results. The unstandardized nature of the production process has been deemed a medium risk to implementation of LCA due to the need for site-specific expertise, which make it difficult to combine studies of multiple sites for producers, as can be the case for other manufactured products.

This leads to another identified systemic problem where goals of LCA studies conducted by producers are generally not set for system improvements through, for example, environmental hotspot identification or identifying the environmental benefits of increasing the amount of recycled input material $[1,21,23,24]$. Although the lack of utilization of LCA for environmental performance improvements can impact the value that can be gained from conducting an LCA by a producer, it is not seen as a risk to implementation or the quantitative results, but could significantly impact improvement results in the long run.

Finally, a lack of industry-specific modelling tools and software to aid environmental management using LCA, particularly those that utilize simulation models in the process, was identified as a systemic challenge for the industry [23-25,29,31]. Although some improvements have been made to LCA software allowing for simulation modelling [24], these still are not specific to the industry and require specialist knowledge. Without appropriate tools or software, the complex modelling of environmental impacts makes LCA inaccessible for most producers. As other tools do exist allowing for implementation, this is not seen as a large risk for implementation into the industry, but can be off-putting for producers where extra input or expertise is needed to utilize current tools effectively. Therefore, a medium risk for both implementation and results was decided.

\subsection{Phase Two: Case Study}

The LCA case study highlighted similar, interconnected challenges to those identified in the literature review, with some additional challenges also noted. In total, six challenges 
were identified: three methodological and three systemic. A summary of the challenges identified is given in Table 2.

Table 2. Summary of identified challenges to evaluating environmental impacts highlighted by the LCA case study.

\begin{tabular}{|c|c|c|c|c|c|}
\hline $\begin{array}{l}\text { Challenge } \\
\text { Classification }\end{array}$ & & Identified Challenge & Impact Stage & $\begin{array}{l}\text { Risk to Imple- } \\
\text { mentation of LCA }\end{array}$ & $\begin{array}{l}\text { Risk to Integrity of } \\
\text { Results from LCA }\end{array}$ \\
\hline \multirow{3}{*}{ Methodological } & 8. & Availability and collection of site-specific data & $\begin{array}{l}\text { Inventory Analysis } \\
\text { (Data quality) }\end{array}$ & High & High \\
\hline & 9. & $\begin{array}{l}\text { Lack of accuracy of site-specific data for } \\
\text { outsourced activities directly contributing to } \\
\text { the manufacturing process }\end{array}$ & $\begin{array}{l}\text { Inventory Analysis } \\
\text { (Data quality) }\end{array}$ & Low & High \\
\hline & 10. & System variability year to year & $\begin{array}{l}\text { Goal and Scope } \\
\text { (System boundaries) }\end{array}$ & Medium & Medium \\
\hline \multirow{3}{*}{ Systemic } & 11. & Allocation of human resources & All stages & High & Low \\
\hline & 12. & Limited applications for the goals of LCA & Goal and Scope & Low & Low \\
\hline & 13. & $\begin{array}{l}\text { Financial burdens associated with the LCA } \\
\text { process }\end{array}$ & All stages & High & Low \\
\hline
\end{tabular}

A majority of the methodological challenges identified were linked to data collection challenges. Some of the data needed to gather a representative Life Cycle Inventory (LCI) for the site were not monitored or recorded, making the process of gathering the necessary data time-consuming and difficult. This included information on diesel consumption for individual machines and purchase information for maintenance inputs that met the cut-off criteria (for example, replacing liners in crushers or panels in screens). A high risk to implementation was identified, mainly due to the connection to the systemic challenge of allocating adequate human resources for conducting the LCA study, as time among staff is already allocated to other tasks (unless their role is directly associated with conducting LCA). This also had a high risk for the results, as data that cannot be collected need to be estimated or omitted, which could have large impacts on the integrity of the results.

Another data-related challenge that can impact the results of the LCA study concerns data collected from outsourced activities directly involved in the manufacturing process, for example drilling and blasting activities. Similarly, there was a lack of monitoring or recording for key inputs, however, one lacked the ability to collect the data from alternative sources (for example, invoices), as the data were outside of the organization. This led to estimates being made for inputs such as diesel consumption based on average estimates per unit of service (for example, per meter drilled) which can have a notable impact on the accuracy of the final results. Despite its high risk to the results, the risk to implementation was deemed low, as estimates can be justified if clearly stated in the LCA study.

The last challenge identified in the methodological classification was linked to difficulties in setting the system boundaries due to variability in the production quantity from fluctuating demands from customers. This means manufacturing processes are rarely similar year on year and have large seasonal fluctuations, making it difficult to decide on a period that can truly represent manufacturing conditions for aggregates leading to a medium risk to results. The risk to implementation has been deemed medium as it can increase the workload for conducting the study, if a longer study period is needed, or the LCA needs to be re-evaluated more regularly to remain relevant.

The systemic challenges identified were generally associated with the role and position of LCA within the company. As discussed earlier, LCA can be time-consuming regarding successively collecting all the required data, and due to the site-specific nature of quarries, on-site personnel will generally need to be involved to gain accurate understandings of the specific manufacturing processes. However, many on-site personnel already have their time allocated towards existing tasks. Therefore, without proper allocation of human resources towards the LCA study, it can be extremely challenging to conduct a site-specific LCA. This challenge has been deemed high risk to implementation, as without the appropriate 
time allocations for staff, an LCA cannot be conducted. The impact to results should be low, unless the scope is redefined for producing a lower quality study because of the lack of resources.

Within the case study organization, LCA was being utilized for the development of EPDs for business-to-business communication purposes. Although this positioning can address challenges associated with the allocation of human resources and financial burdens by giving the LCA study a clear value for the company, it does not encourage the application of LCA for system improvements from an environmental management perspective [42]. This can lead to an underutilization of an LCA study; however, it does not prevent the LCA from being conducted or the affects the quality of the quantitative results, and so was deemed a low risk.

The last systemic challenge was the financial burden that can come from allocating resources towards an LCA study. From the human resources, modelling tools and secondary data, to costs associated with verification and publication of an EPD, an LCA can place a notable economic burden on producers without always having clear financial benefits, especially for small- and medium-sized enterprises (SMEs). As a financial assessment is a common business decision tool, this challenge has been deemed a high risk to implementation and a medium risk to results if appropriate data or tools are not included due to cost savings.

\section{Discussion}

Two of the highest-risk challenges to implementation were identified as systemic challenges of human and financial resource allocation. Unfortunately, possible solutions to the systemic challenges can result in higher risks for methodological challenges and vice versa. For example, commercial LCA software or external LCA consulting can place an economic burden on producers, making it less appealing for environmental management purposes. A possible solution could be to reduce the detail and accuracy of the LCA to ease the process, which could be successful if precise results could still be obtained. The goal and scope would be important if pursuing this action, as LCAs needed for EPD production must meet stricter criteria than an LCA for hotspot analysis, for example. Reducing the number of impact categories or focusing on key contributors (diesel, explosives, and copper in this study), could also save time in data collection, expertise, and money, if precision could be maintained. However, it is important to note that many financial opportunities could be realized through implementing LCA, for example, reaching new customers or markets [11], which can help overcome financial burdens.

These two challenges could also be alleviated if industry-specific software or tools were implemented, which could also address issues with allocation, depending on the capabilities of the tool, and highlights the importance of this challenge. The modelling tools utilized in this study were either outdated (secondary data from 2007) or expensive, and required specialist competencies, confirming findings from the literature that more easily accessible, industry-specific tools would be beneficial to identify environmental improvements for the industry. This would be a good area of investigation for future studies or product development. As LCA is already being utilized for producing EPDs for businessto-business communication, solutions that could integrate this use with environmental management would be beneficial and would avoid wasting resources on conducting similar tasks. The temporal scales of EPDs (currently valid for 5 years) do make them difficult to incorporate into environmental management, and further studies are recommended to successfully integrate both purposes.

The third high-risk challenge to implementation, and the two high-risk challenges to the results, were associated with primary data collection, particularly the difficulties related to collecting relevant data. Better monitoring procedures or implementing sensors to automatically collect relevant data could be implemented to address this.

There were other challenges identified that related to data quality with lower risks. Diesel consumption is a large contributor to environmental impacts at quarries; however, 
from the conditions observed in the case study, over $50 \%$ of diesel consumption was related to subcontractor activities which were difficult to procure accurate data for. Demands for more accurate diesel consumption figures from subcontractors should be encouraged in the future. A lack of secondary data was identified as a challenge in the literature review, but was also noted during the case study, particularly secondary data related to explosives. Unfortunately, there is a lack of datasets in secondary data sources for the variety of explosives used, which can lead to inaccuracies in the results of the LCIA consistent with the medium risk identified in the literature review. As EPDs become more readily available, these should be utilized in modelling tools for impact assessment, particularly for explosives, to gain more accurate representations of how the specific choice of inputs influence the results.

The identification of the same challenge in the literature review and the case study highlights how academia and the industry are working similarly, however the new challenges identified in the case study show the benefits of taking a case study approach in identifying relevant challenges to the specific industrial applications of LCA. Validation studies to see how accurately the identified challenges reflect other organizations and locations are encouraged in the future.

This study aimed to look at LCA as a tool to lead to improvements in environmental performance, and from that perspective, one of the main concerns comes from the systemic challenge of the limited goals of LCA in the industry. From the case study, it is understood that LCA is being utilized in the industry for communication purposes (EPDs) rather than environmental management for identification of improvement areas. The current state of environmental management for quarry sites in Sweden sees most work conducted through regulations and EMS [43]. Monitoring is a mandatory component of an EMS according to ISO 14001:2015, however, this does not imply that environmental impacts themselves are monitored or measured, and is not enough to ensure impact evaluation does take place. LCA can be a great compliment to EMS to quantify environmental impacts, particularly on a global and regional scale, and could help identify areas for improvement. Therefore, a potential environmental management structure including LCA for quarry sites in Sweden is suggested in Figure 1. This aims to address systemic challenges concerning the application of LCA in the industry and build a best-practice framework for environmental management of quarries.

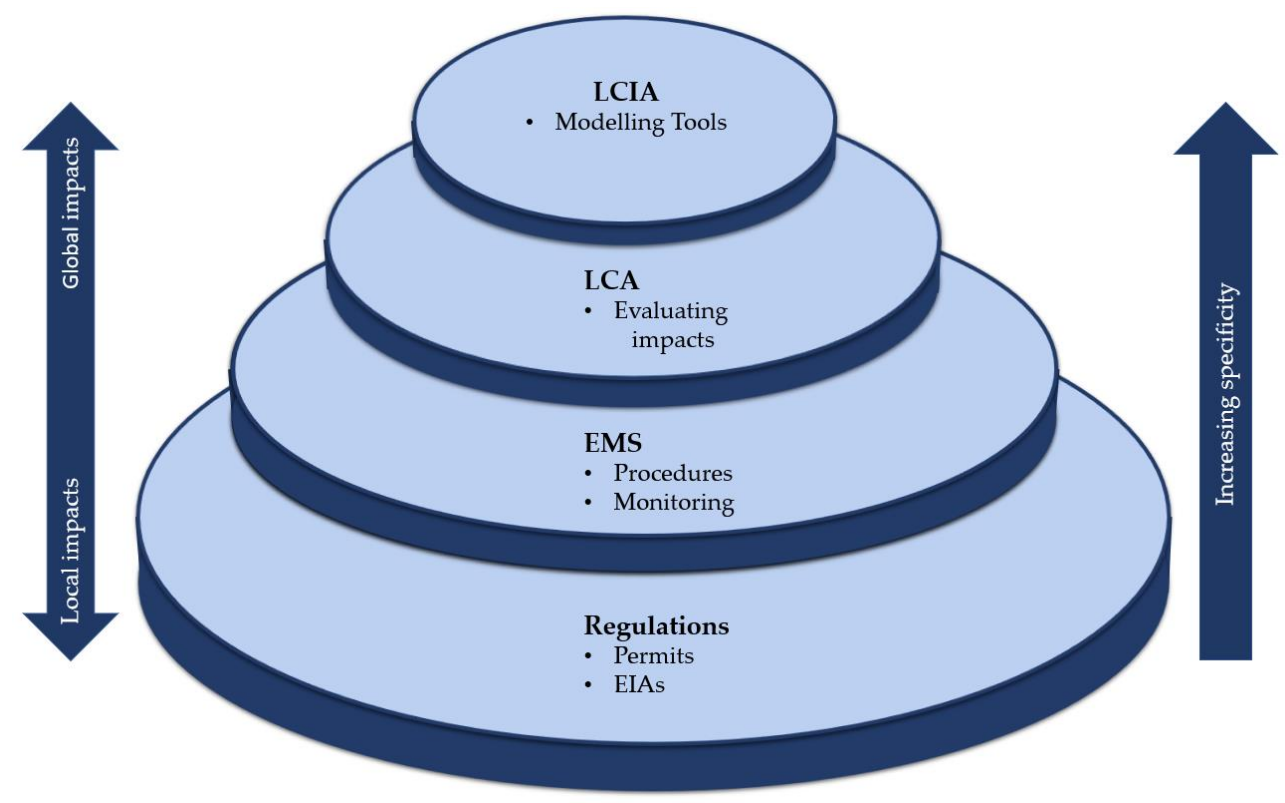

Figure 1. Schematic of suggested environmental management structure that can be utilized in Swedish quarries to illustrate how different techniques can build on and support other techniques while still being individual tools. 
LCA can build on and support existing voluntary and compulsory tools, creating a stronger structure of environmental management for quarries while still being an autonomous technique. By adding a quantitative measurement of impacts, clearer, more precise ambitions and goals for environmental improvement can be set in environmental management, leading to more desired actions and outcomes [44]. The added advantage of implementing LCA within environmental management is that qualitative assessment of impact categories not currently addressed successfully in LCA are still addressed through other techniques, for example, regulations, to ensure they are not overlooked. Other initiatives concerning environmental issues, for example initiatives on biodiversity [45], could also be considered in this framework under the EMS, leading to a more holistic understanding of both local and global environmental concerns.

It is important to consider that this case study looks at one quarry site driven by a large enterprise in Sweden, and the challenges facing, for example, SMEs, could vary. Therefore, further studies are encouraged to compare and validate the identified challenges to help with the implementation of LCA across a wider variety of producers.

\section{Conclusions}

This study has identified seven methodological and six systemic challenges that face aggregate producers when evaluating environmental impacts using LCA. Three challenges are deemed high risk to the implementation of LCA by producers, and two are deemed high risk to the integrity of results from LCA. Two of the high-risk implementation challenges were linked to allocation of financial and human resources, while a third, along with the two high-risk challenges to result integrity, were related to challenges in collecting site-specific data. A best-practice framework is suggested for incorporating LCA into environmental management to overcome some of the medium-to-low-risk challenges that had wider implications for the results of an LCA study, and to encourage system improvements to help meet European and global environmental goals. However, to avoid double work within a company system, communication applications of LCA in the form of EPDs should also be carefully considered, and more research is encouraged to successfully apply LCA for both applications with minimal resources. Several challenges could be addressed through the development of industry-specific tools, as has been suggested in the previous literature, which is validated by this case study, and would be an interesting future line of study. To assess how challenges vary between organizations, particularly between large enterprises and SMEs, further case studies are encouraged in the future.

Author Contributions: Conceptualization, C.L.; methodology, C.L.; formal analysis, C.L., E.H., G.A. and P.P.; investigation, C.L.; data curation, C.L.; writing-original draft preparation, C.L.; writingreview and editing, C.L., E.H., G.A., P.P. and M.E.; visualization, C.L.; supervision, E.H.; funding acquisition, E.H. All authors have read and agreed to the published version of the manuscript.

Funding: This research received funding through VINNOVA under grant number 2019-00857 and the Development Fund of the Swedish Construction Industry (SBUF) under grant number 13738 through the project: Development of a web-based EPD tool for aggregate production.

Institutional Review Board Statement: This study did not require ethical approval as no sensitive personal data was analysed. Procedures were followed to ensure that GDPR was complied with for the collection and analysis of information from persons.

Informed Consent Statement: Informed consent was obtained from all subjects involved in the study.

Data Availability Statement: The data presented in this study are available on request from the corresponding author. The data are not publicly available to maintain the confidentiality of the enterprise.

Acknowledgments: This paper builds on the master's thesis submitted for Christina Lee at the University of Gothenburg within the MSc. Environmental Science program. Our thanks are extended to all those who supported that process. During the case study, support from the Site Manager and other staff members was received in collecting the relevant data, to whom we would also like to extend our thanks. 
Conflicts of Interest: The authors declare no conflict of interest. The funders had no role in the design of the study; in the collection, analyses, or interpretation of data; in the writing of the manuscript, or in the decision to publish the results.

\section{References}

1. Bendouma, S.; Serradj, T.; Vapur, H. A case study of the life cycle impact of limestone quarrying on the environment. Int. J. Glob. Warm. 2020, 22, 432-447. [CrossRef]

2. Jullien, A.; Proust, C.; Martaud, T.; Rayssac, E.; Ropert, C. Variability in the environmental impacts of aggregate production. Resour. Conserv. Recycl. 2012, 62, 1-13. [CrossRef]

3. Korre, A.; Durucan, S. Aggregates Industry Life Cycle Assessment Model: Modelling Tools and Case Studies; Imperial College London: London, UK, 2009.

4. Azadi, M.; Northey, S.A.; Ali, S.H.; Edraki, M. Transparency on greenhouse gas emissions from mining to enable climate change mitigation. Nat. Geosci. 2020, 13, 100-104. [CrossRef]

5. Delevingne, L.; Glazener, W.; Grégoir, L.; Henderson, K. Climate Risk and Decarbonization: What Every Mining CEO Needs to Know. Available online: https://www.mckinsey.com/business-functions/sustainability/our-insights/climate-risk-anddecarbonization-what-every-mining-ceo-needs-to-know (accessed on 6 February 2021).

6. United Nations (UN). The 17 Goals. Available online: https://sdgs.un.org/goals (accessed on 14 June 2021).

7. European Aggregates Association (UEPG). Facts and Figures. Available online: https://uepg.eu/pages/facts (accessed on 12 February 2021).

8. European Commission (EC). A European Green Deal. Available online: https://ec.europa.eu/info/strategy/priorities-2019-202 4/european-green-deal_en (accessed on 30 July 2021).

9. Matthews, H.S.; Hendrickson, C.T.; Matthews, D.H. Life Cycle Assessment: Quantitative Approaches for Decisions That Matter. 2014. Available online: https:/ / www.lcatextbook.com/ (accessed on 21 April 2021).

10. ISO 14040:2006; Environmental Management_Life Cycle Assessment_Principles and Framework; Svensk Standard (SIS): Stockholm, Sweden, 2006.

11. ISO 14001:2015; Environmental Management Systems—Requirements with Guidance for Use; Svensk Standard (SIS): Stockholm, Sweden, 2015.

12. Kaval, P. Measuring and Valuing Environmental Impacts: A Systematic Review of Existing Methodologies; Network for Business Sustainability: London, ON, Canada, 2011; p. 82. Available online: https:/ /www.nbs.net/articles/executive-report-measuringvaluing-environmental-impacts (accessed on 26 July 2021).

13. Baumann, H.; Tillman, A.-M. The hitchhiker's Guide to LCA: An orientation in Life Cycle Assessment Methodology and Application; Studentlitteratur: Lund, Sweden, 2004.

14. Blengini, G.A.; Garbarino, E.; Šolar, S.; Shields, D.J.; Hámor, T.; Vinai, R.; Agioutantis, Z. Life Cycle Assessment guidelines for the sustainable production and recycling of aggregates: The Sustainable Aggregates Resource Management project (SARMa). J. Clean. Prod. 2012, 27, 177-181. [CrossRef]

15. Lee, C.; (Chalmers University of Technology, Sweden). Personal communication, 2021. Private Interview with a Production Engineer on Production and Managment of an Aggregate Quarry \& Production System.

16. Papadopoulou, P.; Asbjörnsson, G.; Hulthén, E.; Evertsson, M. Utilization of environmental simulations in the design and operation of coarse comminution and classification circuit. In Proceedings of the Conference in Minerals Engineering, Luleå, Sweden, 4-5 February 2020.

17. Durão, V.; Silvestre, J.D.; Mateus, R.; De Brito, J. Assessment and communication of the environmental performance of construction products in Europe: Comparison between PEF and EN 15804 compliant EPD schemes. Resour. Conserv. Recycl. 2020, 156, 104703. [CrossRef]

18. Life Cycle Initative (UNEP). Benefits of Life Cycle Approaches. Available online: https:/ /www.lifecycleinitiative.org/startinglife-cycle-thinking/benefits/ (accessed on 6 April 2021).

19. Papadopoulou, P.; Peñaloza, D.; Asbjörnsson, G.; Hulthén, E.; Evertsson, M. Development of a Pre-Verified EPD Tool with Process Simulation Capabilities for the Aggregates Industry. Sustainability 2021, 13, 9492. [CrossRef]

20. Yin, R. Designing case studies: Identifying your case(s) and establishing the logic of your case study. In Case Study Research: Design and Methods, 5th ed.; Knight, V., Ed.; SAGE Publications: Newbury Park, CA, USA, 2014; p. 282.

21. Blengini, G.A.; Garbarino, E. Integrated life cycle management of aggregates quarrying, processing and recycling: Definition of a common LCA methodology in the SARMa project. Int. J. Sustain. Soc. 2011, 3, 327. [CrossRef]

22. Ghanbari, M.; Abbasi, A.M.; Ravanshadnia, M. Production of natural and recycled aggregates: The environmental impacts of energy consumption and $\mathrm{CO}_{2}$ emissions. J. Mater. Cycles Waste Manag. 2018, 20, 810-822. [CrossRef]

23. Segura-Salazar, J.; Lima, F.M.; Tavares, L.M. Life Cycle Assessment in the minerals industry: Current practice, harmonization efforts, and potential improvement through the integration with process simulation. J. Clean. Prod. 2019, 232, 174-192. [CrossRef]

24. Segura-Salazar, J.; Tavares, L.M. A life cycle-based, sustainability-driven innovation approach in the minerals industry: Application to a large-scale granitic quarry in Rio de Janeiro. Miner. Eng. 2021, 172, 107149. [CrossRef] 
25. Asbjörnsson, G.; Hulthén, E.; Evertsson, M. Modelling environmental impacts of aggregates with dynamic simulations. In Proceedings of the 15th European Symposium on Comminution and Classification (ESCC2017), Izmir, Turkey, 11-14 September 2017.

26. Blengini, G.; Garbarino, E. Life Cycle Assessment (LCA) Guidelines: WP3, Activity 3.3. 2011. Available online: http://www. sarmaproject.net/uploads/media/SARMa_LCA_Guidelines.pdf (accessed on 12 February 2021).

27. Hulthén, E. STEM-Projekt Energimodul i Krossanläggningar (Energy Module for Crushing Plants). Ph.D. Thesis, Chalmers University of Technology, Göteborg, Sweden, 2004. Volume 6. pp. 1-22.

28. Santero, N.; Hendry, J. Harmonization of LCA methodologies for the metal and mining industry. Int. J. Life Cycle Assess. 2016, 21, 1543-1553. [CrossRef]

29. Awuah-Offei, K.; Adekpedjou, A. Application of life cycle assessment in the mining industry. Int. J. Life Cycle Assess. 2011, 16, 82-89. [CrossRef]

30. Danielsen, S.W.; Kuznetsova, E. Environmental Impact and Sustainability in Aggregate Production and Use; Springer International Publishing: Cham, Switzerland, 2014; pp. 41-44.

31. Danielsen, S.W.; Kuznetsova, E. Resource management and a Best Available Concept for aggregate sustainability. Geol. Soc. Lond. Spec. Publ. 2016, 416, 59-70. [CrossRef]

32. Rosado, L.P.; Vitale, P.; Penteado, C.S.G.; Arena, U. Life cycle assessment of natural and mixed recycled aggregate production in Brazil. J. Clean. Prod. 2017, 151, 634-642. [CrossRef]

33. Fusch, P.I.; Fusch, G.E.; Ness, L.R. How to conduct a mini-ethnographic case study: A guide for novice researchers. Qual. Rep. 2017, 22, 923. [CrossRef]

34. ISO 14044:2006; Environmental Management_Life Cycle Assessment_Requirements and Guidelines; Svensk Standard (SIS): Stockholm, Sweden, 2006.

35. EN 15804:A1 and PCR 2012:01; Construction Products and Construction Services; Swedish Environmental Research Institute (IVL): Stockholm, Sweden, 2020.

36. Rice, P.; O'Brien, D.; Shalloo, L.; Holden, N.M. Evaluation of allocation methods for calculation of carbon footprint of grass-based dairy production. J. Environ. Manag. 2017, 202, 311-319. [CrossRef] [PubMed]

37. EN 15804:2012+A2:2019; Sustainability of Construction Works_Environmental Product Declarations-Core Rules for the Product Category of Construction Products; Svensk Standard (SIS): Stockholm, Sweden, 2019.

38. Curran, M.; Maia De Souza, D.; Antón, A.; Teixeira, R.F.M.; Michelsen, O.; Vidal-Legaz, B.; Sala, S.; Milà, I.; Canals, L. How Well Does LCA Model Land Use Impacts on Biodiversity?-A Comparison with Approaches from Ecology and Conservation. Environ. Sci. Technol. 2016, 50, 2782-2795. [CrossRef]

39. European Aggregates Association (UEPG). Annual Review 2019-2020; European Aggregates Association: Ixelles, Brussels, 2020.

40. Salgueiro, P.A.; Prach, K.; Branquinho, C.; Mira, A. Enhancing biodiversity and ecosystem services in quarry restorationChallenges, strategies, and practice. Restor. Ecol. 2020, 28, 655-660. [CrossRef]

41. Del Borghi, A.; Moreschi, L.; Gallo, M. Communication through ecolabels: How discrepancies between the EU PEF and EPD schemes could affect outcome consistency. Int. J. Life Cycle Assess. 2020, 25, 905-920. [CrossRef]

42. Rangelov, M.; Dylla, H.; Mukherjee, A.; Sivaneswaran, N. Use of environmental product declarations (EPDs) of pavement materials in the United States of America (U.S.A.) to ensure environmental impact reductions. J. Clean. Prod. 2021, $283,124619$. [CrossRef]

43. Naturvårdsverket. Vägledning om Täkter. Available online: https://www.naturvardsverket.se/Stod-i-miljoarbetet/ Vagledningar/Gruvor-takter-och-markavvattning/Takter/ (accessed on 2 May 2021).

44. Edvardsson, K. Using Goals in Environmental Management: The Swedish System of Environmental Objectives. Environ. Manag. 2004, 34, 170-180. [CrossRef] [PubMed]

45. European Aggregates Association (UEPG). Roadmap to 2030; European Aggregates Association (UEPG): Ixelles, Brussels, 2021; Available online: https://uepg.eu/mediatheque/index/0.html (accessed on 16 November 2021). 